\title{
Cement Bonded Particle Boards with Different Types of Natural Fibres-Using Carbon Dioxide Injection for Increased Initial Bonding
}

\author{
Björn Marteinsson 1,2*, Edgar Gudmundsson ${ }^{3}$ \\ ${ }^{1}$ Faculty of Civil and Environmental Engineering, University of Iceland, Reykjavik, Iceland \\ ${ }^{2}$ Innovation Center Iceland, Reykjavik, Iceland \\ ${ }^{3}$ Speca, Reykjavik, Iceland \\ Email: *bjomar@hi.is
}

How to cite this paper: Marteinsson, B. and Gudmundsson, E. (2018) Cement Bonded Particle Boards with Different Types of Natural Fibres-Using Carbon Dioxide Injection for Increased Initial Bonding. Open Journal of Composite Materials, 8, 28-42. https://doi.org/10.4236/ojcm.2018.81003

Received: November 21, 2017

Accepted: January 6, 2018

Published: January 9, 2018

Copyright $\odot 2018$ by authors and Scientific Research Publishing Inc. This work is licensed under the Creative Commons Attribution International License (CC BY 4.0).

http://creativecommons.org/licenses/by/4.0/

\begin{abstract}
The effect of $\mathrm{CO}_{2}$ injection on initial strength increase and hardening of cement-fibre mix in a cement bonded particle board ( $\mathrm{CBPB}$ ) production was evaluated. Different cement contents, formation pressure and types of fibres were considered. The initial strength increase with $\mathrm{CO}_{2}$ injection is so much faster than this caused by conventional hydration that the produced samples do not need additional curing before they can be stored. Similar strength and stiffness values as in conventional products on the market are gained with lower cement content for similar types of fibres. Visual inspection of board surfaces aged for 13 years in a harsh exterior environment as well as comparison of strength and stiffness values for these boards when new and after ageing, gives a very satisfying result. The combined effect of the above discussed gains results in markedly increased productivity at lower cost and lower environmental impacts than is possible in traditional CBPB production.
\end{abstract}

\section{Keywords}

Fibre Cements, Carbon Dioxide, Initial Hardening, Natural Fibres, Strength, Durability

\section{Introduction}

Cement bonded particle boards (CBPB) are traditionally made of wood fibres, cement and water, usually with some additives to speed up the bonding process, in traditional production caused by hydration of cement. CBPB boards so far, 
due i.e. to economic reasons are only used to a very limited extent, compared to common boards with organic binder (plywood, OSB). However, the CBPB boards have very interesting properties regarding stiffness, fire, acoustics and resistance to termites and microorganisms.

There are mainly two different methods in use to produce CBPB; the Hatscheck process and the Elmendorf process. Initially, asbestos fibres were used whereas now these comprise cellulose fibres; fibre length up to $4 \mathrm{~mm}$ (commonly less than $3 \mathrm{~mm}$ ), diameter typically around $40 \mu \mathrm{m}$.

\section{The Hatscheck Process}

A drum rotates in a water based slurry of fibres and mineral materials, including Portland cement. The drum feeds a film of slurry onto a felt while simultaneously partially pressing the water from the film, upon which the felt moves the film onto a forming roller where a sheet of desired thickness is built up by a number of turns. Subsequently, the stack of films is removed from the roller and laid out flat to form the sheet.

\section{The Elmendorf Process}

Fibres, water and then cement are thoroughly mixed, with the mix typically made with fibres amounting about $70 \%$ of the volume; with the ratio by weight: cement $60 \%$, wood $20 \%$, water $20 \%$. The damp matrix is fed continuously onto a bottom (caul) plate to form a mat. The caul plates with mats are stack-pressed to yield boards of desired thickness. Under the pressure, of 1.5 - 3.0 MPa, water squeezes out of the wood particles and combines with the cement to form a paste. The stack of boards is clamped together at this pressure and moved to a curing cabinet, with controlled humidity and temperature $\left(70^{\circ} \mathrm{C}-80^{\circ} \mathrm{C}\right)$ and left there for curing for 8 - 20 hours [1] [2].

The CBPB boards are of interest as these have good fire protection properties, along with better resistance to humidity fluctuations than most comparable boards on the market. The inorganic binding material (cement) gives better resistance to microorganisms than boards with organic binders [1] [3] [4]. The boards are rather heavy compared to other types of boards used in construction and therefore often used for specialized applications indoors and outdoors e.g. as external claddings in Austria, Canada, Hungary, Iceland and Japan. Still, up until now the price of these boards has been higher than this for other boards competing on the market which has negatively affected more general use of the boards.

The initial strength increase of cement bonds is traditionally acquired by hydration followed with time by additional strength gained through carbonation of the hardened cement paste. Usually carbonation, due to changes in $\mathrm{pH}$ of the concrete and also additional shrinkage, is considered as a deterioration mechanism in reinforced concrete but the mechanism certainly has its positive sides too as e.g. substantiated by testing.

It has been known for decades that initial hardening of the cement paste by accelerated carbonation can be achieved by the injection of $\mathrm{CO}_{2}$ into the wet 
paste. The initial reaction on exposure to $\mathrm{CO}_{2}$ is an accelerated hydration of the silicates to form a calcium silicate hydrate (C-S-H) like gel and calcite, while furthermore the reaction is exothermic [5] [6]. The amount of reaction results after $3 \mathrm{~min}$. in the accelerated hydration similar to this after $12 \mathrm{~h}$ in traditional hydration [6].

Tests on cement paste, with initial hardening by $\mathrm{CO}_{2}$ injection, with or without fibres, described in the literature vary with respect to both type of specimens and methodology. In the earliest tests bulk specimens were used, made of cement paste only, and specimens are placed in a chamber fed with predefined $\mathrm{CO}_{2}$ pressure and concentration [5] [6] [7]. The effect of carbonation curing on zero-slump dry mix concrete for precast production is discussed by Rostami et al. [8]. In a number of tests (thin) board specimens of cement paste and fibres are tested, usually with $\mathrm{CO}_{2}$ injection from both sides, often cycled with vacuum in specimen. Effect of different $\mathrm{CO}_{2}$ pressure and/or concentration is also evaluated [2] [9]. In one case, injection from one side is noted and it is shown that this does not affect the final results [2]. It is further found that the speed of the carbonation reaction increases with increased $\mathrm{CO}_{2}$ pressure and concentration. In a cement paste, a high water-cement ratio will slow down the diffusion of $\mathrm{CO}_{2}$ as shown in various tests where the $\mathrm{w} / \mathrm{c}$ ratio is oftentimes as low as $0.1-0.2$ [5] [6] [7] [9]. In specimens with cellulose fibres embedded in the cement paste, the w/c ratio can be higher without affecting the $\mathrm{CO}_{2}$ exposure as the fibres themselves are rather open to diffusion [2]. The optimum formation pressure on specimen is found to be dependent on the $\mathrm{w} / \mathrm{c}$ ratio, higher $\mathrm{w} / \mathrm{c}$ ratio needs lower pressure [7]. Strength and stiffness of boards increases with higher cement-wood ratio up to a certain limit where the mechanical properties start declining [10]. As the cost for cement is an important part in the total cost, it is important to optimize the cement amount. $\mathrm{CO}_{2}$ curing reduces the capillary pore volume in both un-aged and aged specimens, which then will result in a more favourable moisture stability [9] [11].

Agopyan [12] discusses use of vegetable fibre-cement based materials. $\mathrm{He}$ mentions that the alkaline cement paste weakens most natural fibres and that reduced alkalinity may be reached by fast carbonation processes as discussed by Savastano et al. [13]. The fast carbonation of CBPB may thus allow the use of various agricultural waste fibres which due to durability consideration have not been considered in traditional production.

Initial hardening by $\mathrm{CO}_{2}$ exposure may result in new interesting development techniques in the production of СВРB boards. For the accelerated carbonation, $\mathrm{CO}_{2}$ in a much higher concentration than this in the atmosphere is needed, and the resulting $\mathrm{CO}_{2}$ sequestration is of interest in itself [14]. The faster strength increase by use of $\mathrm{CO}_{2}$ injection can be used to shorten the production time and thus increase the production efficiency and lower the pertinent production costs.

In 1986 E. Schmidt, Dr. Dipl.-ing [15], patented a method for initial hardening of СВРB. The method presumed for the use of wooden fibres as a replacement 
for asbestos in cement bonded boards. Falco Fakombinát Szombáthély (Hungary) in cooperation with Rauma Repola Oy (Finland) then operated an experimental factory using the method in Hungary for a few years but this was abolished in the aftermath of the collapse of the Soviet Union.

An EU research project with the former Icelandic Building Research Institute (IBRI), now Innovation Centre of Iceland, as project leader was ongoing in the time period 1997-2000. The aim of the project was to develop a production method for box house elements of wood-fibre and cement in one pressing operation, using fast initial carbonization to speed up the hardening process. The project resulted in a patented production method [16]. Subsequently, a test production line was operated from year 2000 until 2007, when it was clear that the method needed further development and the costs would be too high for the owners.

To the knowledge of the authors of this paper there is no full scale production line functioning any longer where initial hardening of cement bonded material by $\mathrm{CO}_{2}$ injection is used.

The properties of CBPB compared to other board materials should be of interest to the building market. Especially with the use of $\mathrm{CO}_{2}$ injection, various types of fibres, e.g. waste materials from agriculture might be used. It is therefore of great interest to develop faster, cheaper and more environmentally friendly production techniques of CBPB; with lower cement content, less energy use, as curing cabinets will not be needed, to the same extent as at the present and the possibility of using non-traditional fibres such as re-used wood or waste fibres from agriculture such as bagasse.

In 2010 research on the use of fast carbonation in CBPB production was reintroduced at the Innovation Centre of Iceland in cooperation with SPECA (Iceland), with the main aim of testing fibres from agricultural waste; wheat- and barley straw to produce boards.

The aim of this paper is i.e. to describe tests on CBPB with wood fibres, comparison of $\mathrm{CO}_{2}$ injected $\mathrm{CBPB}$ with traditional $\mathrm{CBPB}$, and then test results from small laboratory $\mathrm{CBPB}$ specimens with wheat fibres and $\mathrm{CO}_{2}$ injection.

\section{Materials and Methods}

In the EU research project noted earlier [16] developing box elements for houses one of the participants represented a СВPB producer. In the initial stage of the project, small scale test pieces produced in laboratory were compared with test results from specimens taken out of full scale factory production; in both cases exactly the same material mix being used.

In factory production a feeder is used to form the mat on a moving caul plate, as mentioned earlier. The method results in a felt of a stable quality and it is known from experience of fibre board production that this is very important for the quality of the product. In the laboratory tests there was no access to a feeder so that a box forming the specimens was hand fed through a screen. The relevant 
result is thus not of the same quality as from a factory feeder. In the research project the effect of this had to be evaluated, and therefore results from measurements on specimens taken from factory production were compared with those from a laboratory production, using exactly the same material mix.

Test specimens in the research were of four types: 1) small scale specimens with traditional wood fibres, made in a laboratory simulating traditional CBPB production, 2) specimens taken from factory made CBPB boards in Europe, 3) small scale specimens with different fibre types made in the laboratory with initial $\mathrm{CO}_{2}$ hardening and finally, 4) specimens from full scale cement fibre box elements with initial $\mathrm{CO}_{2}$ hardening produced at an early stage of the aforementioned research project in Germany, and later with the factory products using $\mathrm{CO}_{2}$ produced in Iceland. In all cases the mixing of materials and production was in accordance with the Elmendorf process, not the wet slurry method of Hatscheck.

The main part of the research was aimed at evaluating the effect of fast initial hardening with $\mathrm{CO}_{2}$ injection. The method used is similar to this described by Simatupang et al. [2], in the project presented initially with $\mathrm{CO}_{2}$ feeding from two sides but later on from only one side, and always without any air suction from specimens.

Cement and material mix:

Cement used was standard Type I Portland cement. The basic material mix is cement/fibre (bone dry) ratio of 2.8, the water/cement ratio 0.28 and with some additional, yet limited water in the fibres. For plain wood fibres, the total water content then results in a water/cement ratio of 0.32 .

All mixes were without any additives commonly used in $\mathrm{CBPB}$ production.

Fibre type and size:

The wood fibres used in the testing project were in the initial stage imported spruce fibres from a big CBPB producer in Europe, but after full scale production started, the fibres were produced in Iceland from reused freight pallets. For comparison, fibres from barley and wheat stems were also used. The stems are dried to make the material more brittle makes it possible to hack the stems in a high speed mixer to produce the fibres. The method is simplistic but it was difficult to get even product, the particle size being dependent on i.e. the amount hacked each time and the time the mixer is on-a refinement of the fibre forming process will be needed.

The production of wood fibres for CBPB production is an industry, using well-defined fibres, and is well proven over time. While evaluating new type of fibres it is natural to compare these with the traditional fibres. In the test production of boards, the fibres used were traditional wood fibres (for comparison) along with fibres from different plants. For the sake of comparison between fibre types the three dimensions; thickness, width and length can be compared, Table 1. The particle size distribution itself is similar in both cases, Figure 1. The straws were generally thin in one direction perpendicular to length and width 
Table 1. Size of different fibres used.

\begin{tabular}{cccc}
\hline Type of fibres & Diameter (mm) & $\begin{array}{c}\text { Typical length of dominant } \\
\text { particle size }(\mathrm{mm})\end{array}$ & Longest fibres (mm) \\
\hline Wood & $0.6-2.2$ & $6-10$ & 19 \\
Barley straw (Iceland) & $0.2-2.2$ & $10-12$ & 86 \\
\hline
\end{tabular}

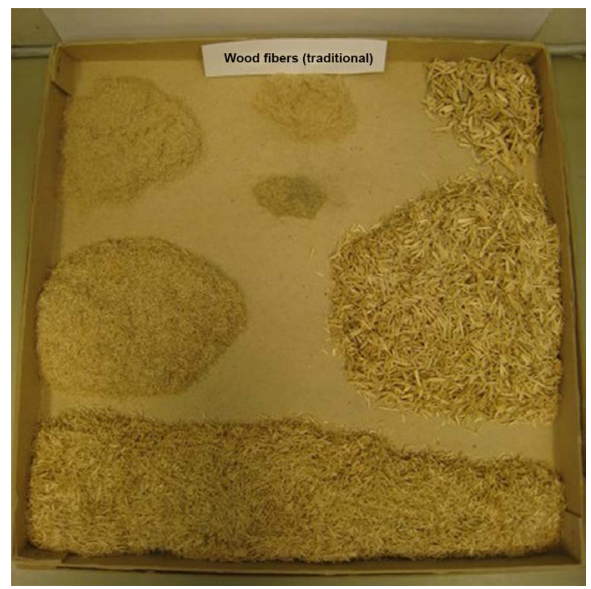

(a)

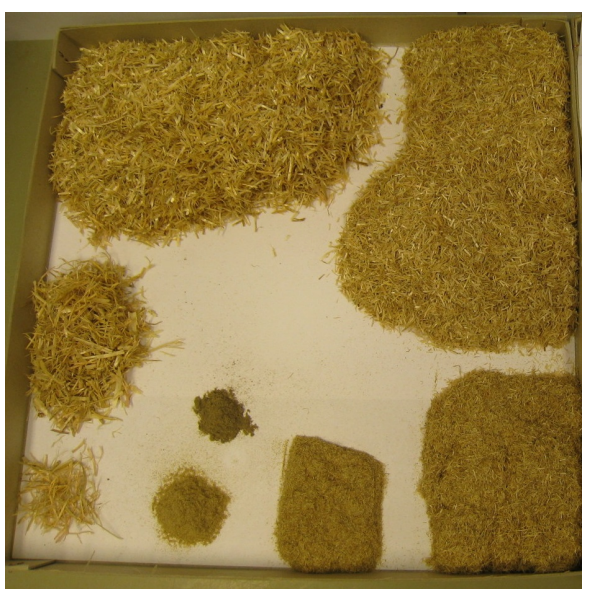

(b)

Figure 1. Proportion of different particle sizes. (a) Traditional wood fibres; (b) Fibres from barley straw.

that is a few times the thickness, the sizes perpendicular to length often change noticeably (the uniformity of these fibres is less than for the wood fibres).

The particle distribution is measured by quadratic mesh sieves that are vibrated to get the fibres through; the larger dimension of thickness or width will be determining for the measured distribution but the smaller dimension will be more typical measured perpendicular to the plane due to the effect of production pressure.

Laboratory specimens' production:

The specimen produced in the laboratory were of the size of $42 \times 48 \mathrm{~cm}$ with aimed at thickness usually $12 \mathrm{~mm}$, while actual thickness varied somewhat pending on type of fibres, material mix and formation pressure.

The mixing of materials was done in a Hobart mixer by adding water to the fibres, and allowed to mix for $2 \mathrm{~min}$. to get an even moisture distribution. Cement was then added in small amounts into the mix with the mixer going all the time. The material matrix was handfed onto a plate and then pressed.

The traditional CBPB production is simulated by keeping the formation pressure of $1.5 \mathrm{MPa}$ for 12 hours and the stack is enclosed in polyethylene film all the time so as not to lose moisture from the board by evaporation. The stack is also insulated and the hydration heat and additional energy used to keep the temperature at $60^{\circ} \mathrm{C}$ or close to this. After the 12 hours the specimen was put in a curing cabinet at $20^{\circ} \mathrm{C}$ and $50 \% \mathrm{RH}$.

For specimen intended for $\mathrm{CO}_{2}$ injection from one side the material matrix is 
fed onto a perforated plate to allow injection of $\mathrm{CO}_{2}$ into the matrix. When injected from both sides a similar plate was placed on top of the matrix before placing the stack into the loading apparatus, Figure 2. In all the tests, pure (undiluted) $\mathrm{CO}_{2}$ was used. The $\mathrm{CO}_{2}$ pressure applied was 2 atm ( 2 bars), total pressure time was 4 - 5 minutes with the forming pressure either 1.5 or $2.5 \mathrm{MPa}$. The fibres always give some spring back effect after the pressure is relieved which may damage the specimen. Therefore, care needs to be taken so that the additional internal $\mathrm{CO}_{2}$ pressure is cut off before the formation pressure is decreased.

Bending test of specimen:

Determination of bending strength and stiffness is made according to EN 310 [17] in a three-point loading test; a load on the centre of a test piece supported at two points. The thickness of the test piece is symbolized by $t$, width $b$ of the specimen $50 \pm 1 \mathrm{~mm}$, distance between supports $l_{1}=20 \mathrm{t}$ and the total length of specimen $\mathrm{l}_{2}=\mathrm{l}_{1}+50 \mathrm{~mm}$.

The bending stiffness is determined from the load-deflection curve from load and deflection at loads $0.1 \mathrm{~F}_{\max }$ and $0.4 \mathrm{~F}_{\max }$.

From each board, made in the laboratory or from full scale production, five specimen of a certain size were acquired to fulfil the standard requirements, the thickness of boards, and specimen, varied between 12 and $20 \mathrm{~mm}$.

\section{Test Results and Discussion}

\subsection{Cement Bonded Wood Fibre Boards}

The specimen and products discussed in this part of the paper are all made from either virgin spruce fibres or recycled wood products from freight pallets.

\subsubsection{Comparison of Traditional CBPB in a Small Scale Specimen and Full Scale Factory Production}

Small scale specimens were produced in the laboratory simulating the traditional CBPB production as described earlier, the specimen were stored for seven days in a curing cabinet at $20^{\circ} \mathrm{C}, 50 \% \mathrm{RH}$ before testing. Additionally, test specimens were cut from full size boards produced in a CBPB factory in Germany. The test results from bending tests of these two types of test specimen are shown in Table 2. The fibre content and the type are the same in both mixes while the cement content differed somewhat, in the small scale specimen $790 \mathrm{~kg} / \mathrm{m}^{3}$ but nearer to $900 \mathrm{~kg} / \mathrm{m}^{3}$ in the full scale specimens.

The results show that the results from the small scale production of test pieces were consistent in themselves but much lower than the results from the full scale production. For comparison with the traditional СBPB market, it should be noted that boards on the European market from two big producers have a stated bending strength of $12 \mathrm{MPa}$. Based on the evaluated strength and stiffness difference of test pieces from small and large scale production the small scale production was considered valuable in evaluating the effect of different production methods and material mixes, keeping in mind that the full scale products would 


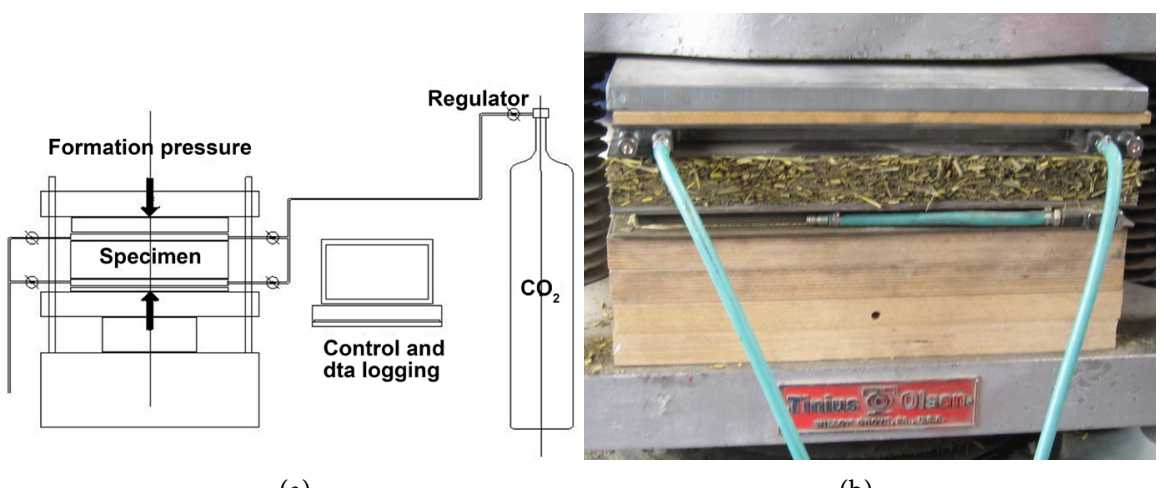

(a)

(b)

Figure 2. Loading apparatus, with perforated plates for $\mathrm{CO}_{2}$ injection and $\mathrm{CBPB}$ specimen.

Table 2. Traditional production of $\mathrm{CBPB}$ results from bending tests on small laboratory specimens and full scale factory specimens; average values (standard deviation in parenthesis).

\begin{tabular}{ccccc}
\hline & No of tests & $\begin{array}{c}\text { Density } \\
\left(\mathrm{kg} / \mathrm{m}^{3}\right)\end{array}$ & $\begin{array}{c}\text { Bending strength } \\
\text { MOR (MPa) }\end{array}$ & $\begin{array}{c}\text { Bending stiffness } \\
\text { MOE (MPa) }\end{array}$ \\
\hline $\begin{array}{c}\text { Small laboratory specimens } \\
\text { Full scale specimens }\end{array}$ & 24 & 1333.4 & $5.1(0.78)$ & $1754(374.5)$ \\
\hline
\end{tabular}

be considerably stronger. The higher strength in a full scale production using initial hardening by $\mathrm{CO}_{2}$ was later in the project proven to be the case. Based on this, further tests on small scale test pieces with initial $\mathrm{CO}_{2}$ hardening were made to evaluate the effect of ageing, amount of cement and types of fibres.

\subsubsection{Small Scale Laboratory Specimens with Initial Hardening by $\mathrm{CO}_{2}$ Injection}

Small scale laboratory specimens ere produced with initial hardening by $\mathrm{CO}_{2}$ injection from both sides. The matrix mix is the same as in traditional CBPB tested, the cement content about $800 \mathrm{~kg} / \mathrm{m}^{3}$. The test results are shown in Table 3 .

By comparing values in Table 2 and Table 3 it can be seen that boards with initial hardening by $\mathrm{CO}_{2}$ injection (Table 3 ) reach in one day $89 \%$ of the seven days bending strength of traditionally produced boards (Table 2). The strength increase is then slow the following days, and at seven days' age the strength has reached $98 \%$ of the strength of the traditionally produced board at same age.

Small scale specimen with different cement content and initial hardening by $\mathrm{CO}_{2}$ from both sides were tested, a total of 24 test pieces for each type of mix. Water content is somewhat higher than in the tests already described; $15 \%$ of dry weight of fibres $+0.30 \mathrm{w} / \mathrm{c}$ ratio. Formation pressure was either $1.5 \mathrm{MPa}$ or $2.5 \mathrm{MPa}$, and tests done after curing of specimens for respectively 1 and 10 weeks. Figure 3 shows how bending strength varies with cement content, forming pressure and age (each point presents an average value of 8 tests). 
Table 3. Small scale laboratory specimens produced with initial $\mathrm{CO}_{2}$ hardening-results from bending tests at different ages of specimen; average values (standard deviation in parenthesis).

\begin{tabular}{cccc}
\hline Conditioning (days) & No of tests & $\begin{array}{c}\text { Bending strength MOR } \\
(\mathrm{MPa})\end{array}$ & $\begin{array}{c}\text { Bending stiffness MOE } \\
(\mathrm{MPa})\end{array}$ \\
\hline 1 & 45 & $4.54(1.07)$ & $1849(587)$ \\
7 & 33 & $5.01(0.88)$ & $2141(524)$ \\
28 & 33 & $6.21(1.46)$ & $2693(576)$ \\
\hline
\end{tabular}

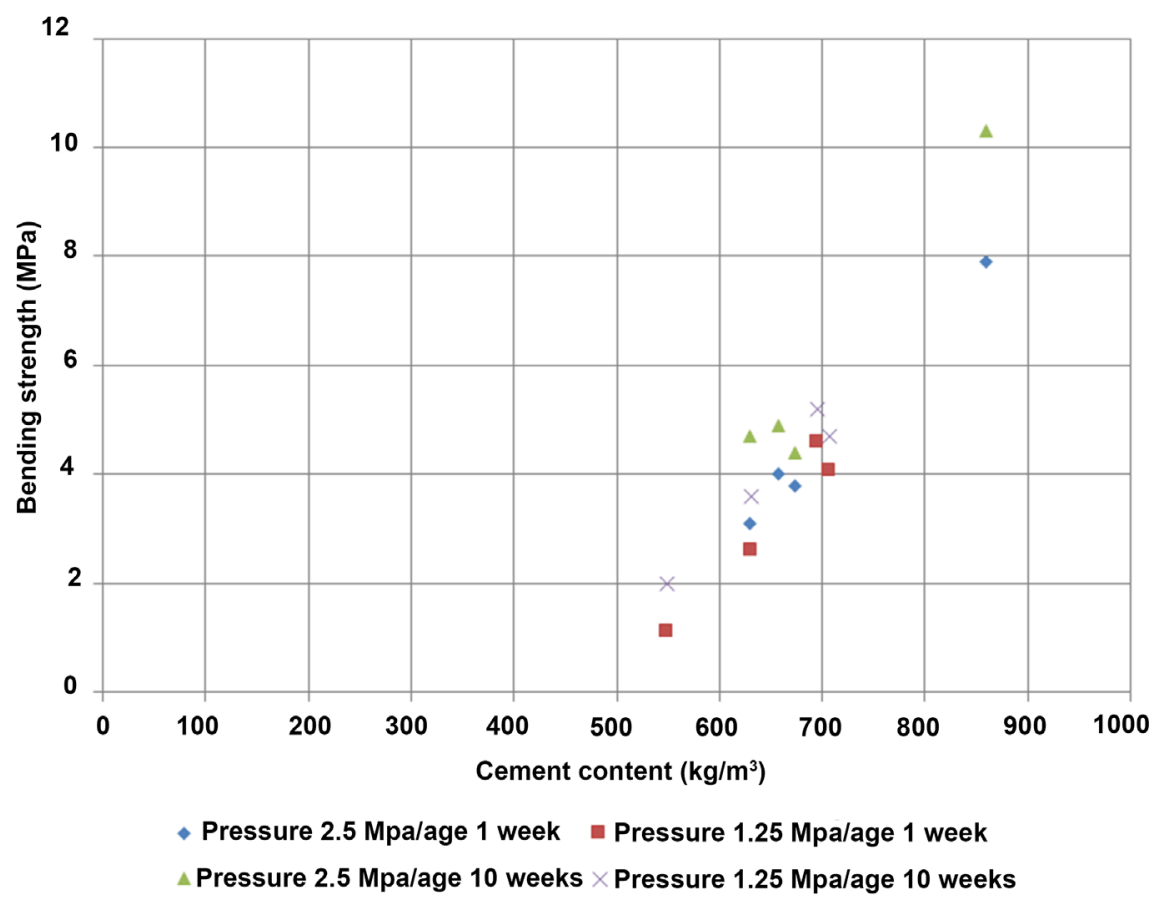

Figure 3. Bending strength varies with cement content, formation pressure and age.

The test results may be summarized as follows:

1) Bending strength (and also density and stiffness, not shown on figure) of specimens increases significantly with increased cement content given the same formation pressure.

2) Increased formation pressure makes denser and somewhat stronger products.

3) Bending strength increases significantly with age from 1 week to 10 weeks.

Generally, the variability in results from the small scale specimen is considerable and so quite a number of test pieces are required to get reliable results. Measured moisture adsorption on a very limited number of pieces indicates that equilibrium moisture of the $\mathrm{CO}_{2}$ hardened pieces is considerably lower than for the factory produced CBPB boards and that the first mentioned pieces also have smaller dimensional changes due to moisture changes. This can be explained by the findings of Fan et al. [18], which attribute dimensional changes in CBPB to combined effects of moisture reaction, carbonation of the cement paste, and 
degradation of the wood chips.

Limited test series with only eight specimens of each type were used to compare strength results of pieces produced with $\mathrm{CO}_{2}$ injection from both sides with pieces injected from one side only. The results indicate that specimen produced with single sided injection are as good as these produced with double sided injection.

\subsubsection{CBPB with Initial Hardening by $\mathrm{CO}_{2}$ Injection-Comparison of Bending Strength between Small and Full Scale Production}

Test results on specimen with $\mathrm{CO}_{2}$ injection from small scale elements were compared with results from specimens from full scale element factory production. The matrix mix is exactly the same in both types of elements; wood fibres (bone dry) $275 \mathrm{~kg} / \mathrm{m}^{3}$, water $245 \mathrm{~kg} / \mathrm{m}^{3}$, cement Type I $770 \mathrm{~kg} / \mathrm{m}^{3}, \mathrm{CO}_{2} 80 \mathrm{~kg} / \mathrm{m}^{3}$ and formation pressure 2.5 $\mathrm{MPa}$. The small and full scale specimen compared were of exactly the same mix and the production methodology as similar as possible (only the feeding of matrix differs). The results are in Table 4 and show that the full scale production is much stronger than the small scale one. The measured strength in the full scale specimen is well above the $12 \mathrm{MPa}$ customary in CBPB on the market. To get similar strength characteristics for the initially hardened products as is typical for common $\mathrm{CBPB}$ products, it should be possible to use less cement than was in the prototype element production.

\subsection{CBPB Boards Produced with Barley Fibres}

Agricultural materials such as wheat and barley stems are available in abundance worldwide. Thus it is of interest if such fibres can be used in CВPB. A few specimens were produced in the laboratory and tested after seven days curing in the same way as already described for other small scale specimen. The cement content was $900 \mathrm{~kg} / \mathrm{m}^{3}$, one sided $\mathrm{CO}_{2}$ injection used and formation pressure 1.5 MPa. The test results are shown in Table 5. Even with the high cement content of $900 \mathrm{~kg} / \mathrm{m}^{3}$ both strength and stiffness is lower than in tested specimens with wood fibres with cement content of $700-800 \mathrm{~kg} / \mathrm{m}^{3}$ (Figure 3). Regardless, the main thing in this context is that the fibres can be used in CBPB.

\subsection{Experience of CBPB, Initially Hardened by $\mathrm{CO}_{2}$ Injection, In Iceland}

A full scale factory production was operated for some years in Iceland as mentioned earlier, using the same mix as already described for the full scale test elements. Throw away elements from this production period, specimens that were

Table 4. Test results from bending tests, initial $\mathrm{CO}_{2}$ hardening; small scale laboratory production compared with full scale factory production (28 days conditioning).

\begin{tabular}{ccccc}
\hline Type & No. of tests & $\begin{array}{c}\text { Density } \\
\left(\mathrm{kg} / \mathrm{m}^{3}\right)\end{array}$ & $\begin{array}{c}\text { Bending strength } \\
\text { MOR }(\mathrm{MPa})\end{array}$ & $\begin{array}{c}\text { Bending stiffness } \\
\text { MOE (MPa) }\end{array}$ \\
\hline Small scalelab. specimen & 33 & 1235 & $6.2(1.5)$ & $2693(576)$ \\
Full scale specimen & 40 & $1461(99)$ & $15.8(2.1)$ & $8417(1396)$ \\
\hline
\end{tabular}


Table 5. Bending strength and stiffness for specimens with barley stem fibres.

\begin{tabular}{cccccc}
\hline Type & No. of tests & $\begin{array}{c}\text { Age } \\
(\text { days })\end{array}$ & $\begin{array}{c}\text { Density } \\
\left(\mathrm{kg} / \mathrm{m}^{3}\right)\end{array}$ & $\begin{array}{c}\text { Bending strength } \\
\text { MOR (MPa) }\end{array}$ & $\begin{array}{c}\text { Bending stiffness } \\
\text { MOE (MPa) }\end{array}$ \\
\hline \multirow{2}{*}{ Barley stem fibres } & 4 & 6 & $1415(18)$ & $4.9(0.85)$ & $2407(129)$ \\
& 4 & 13 & $1447(4)$ & $6.5(0.40)$ & $2832(228)$ \\
\hline
\end{tabular}

not approved in the quality control inspection, still exist in an unprotected stack outdoors at the factory site. There also stands an extension building to the production hall; built in 2003 from СВРB box elements. The walls are unprotected by any surface treatment. The climate is moist and windy with frequent freeze-thaw periods; the yearly precipitation is $600-800 \mathrm{~mm}$, humidity all year round about $80 \% \mathrm{RH}$ and number of annual freeze-thaw cycles ranges 45 - 55. A visual inspection shows a slight surface roughening at spots on the surface of wall-elements, Figure 4. Specimens were cut from elements that had been stored horizontally, but unprotected, for 13 years or so.

The moisture content in some elements along with the factory wall element was measured with a capacitive moisture meter for comparison. Moisture in the wall elements was similar to the driest unused elements. Pieces were cut from five of the stacked box elements, Figure 5, and acclimatized in the laboratory for two weeks at $20^{\circ} \mathrm{C}$ and $50 \% \mathrm{RH}$. From each piece then five specimens were cut and measured in laboratory. The test results are shown in Table 6 and Figure 6. The load-deflection curves are very regular with almost a linear increase in deflection with load up to $75 \%-80 \%$ of ultimate load. After lying 13 years outdoors with no rain protection, and in some cases rather high moisture content, the measured strength is similar to this measured in new elements produced in the time-interval 2001-2002 but stiffness is somewhat lower (Table 4). As already mentioned above, and also by Dinwoodie and Paxton [3] for traditional CBPB, there is an increase in strength over time - which in the case studied is over a 13 years time period of similar value as that caused by degradation. Both visual inspection and measured strength and stiffness show a very satisfying behaviour over time.

\section{Conclusions}

The research project gave many interesting results regarding initial hardening following $\mathrm{CO}_{2}$ injection into the newly pressed $\mathrm{CBPB}$ with traditional wood fibres compared to similar production without $\mathrm{CO}_{2}$ injection, and furthermore that other types of fibres can be used in this context.

Small scale laboratory production yields less strength and stiffness properties than products from a full scale production. This difference is mainly due to uneven feeding (by hand) of the matrix in a small scale production. The small specimens show a greater variability in properties than does a full scale production. The difference makes for a fairly exact estimate of which results may be expected in full size production somewhat uncertain. 


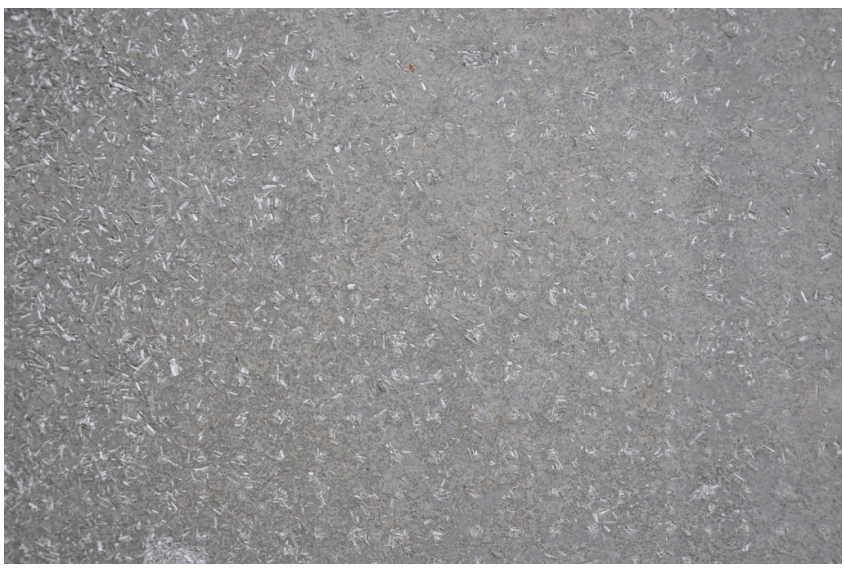

Figure 4. The unprotected surface of a box element in wall of the factory building (after 13 years outdoor weathering).

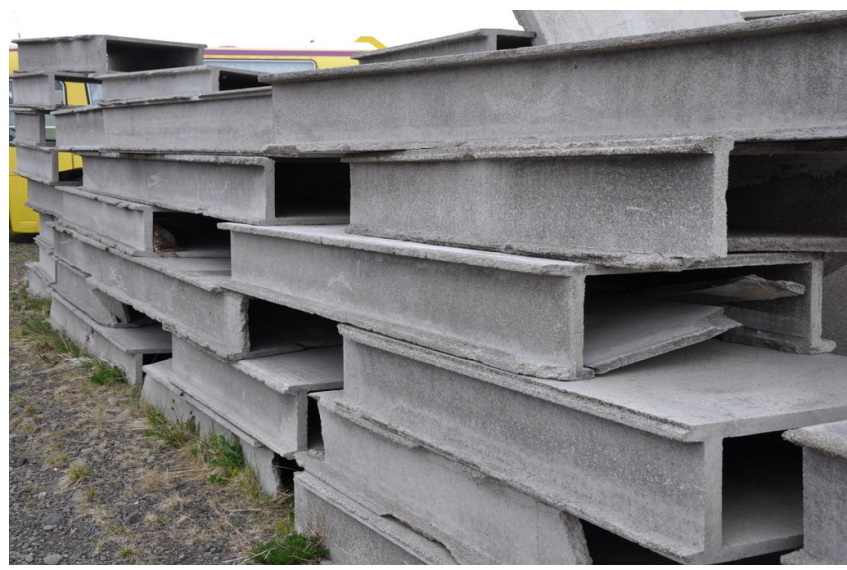

Figure 5. Faulty CBPB box elements stacked outdoors.

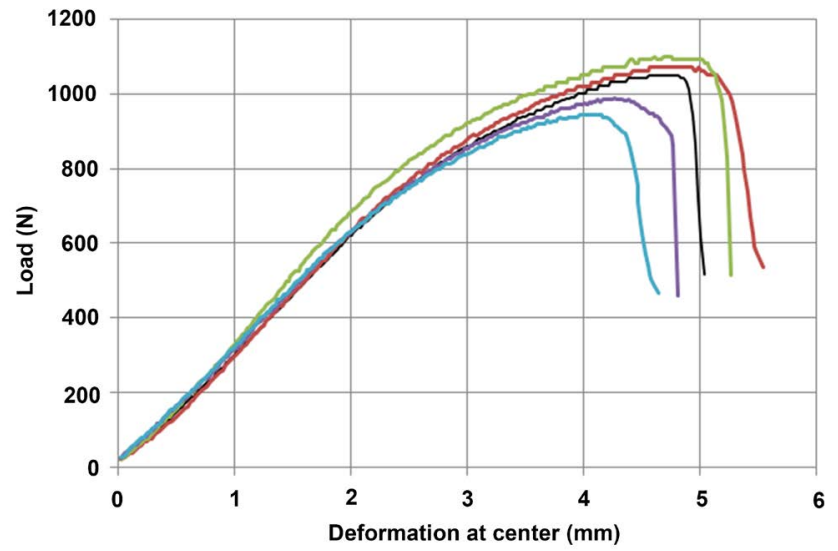

Figure 6. Load-deflection curves for five specimen cut from the same board.

Measured dimensional changes due to moisture changes in CBPB produced with $\mathrm{CO}_{2}$ injection are considerably lower than in traditional CBPB.

The initial hardening with $\mathrm{CO}_{2}$ injection does not need any extra energy for heating of the boards, and also less cement use than is needed in traditional 
Table 6. Bending strength and stiffness of initially hardened $\mathrm{CBPB}$ with $\mathrm{CO}_{2}$; elements aged 7 days and after 13 years of weathering.

\begin{tabular}{cccccc}
\hline & $\begin{array}{c}\text { Number of Thickness } \\
\text { test-pieces } \\
(\mathrm{mm})\end{array}$ & $\begin{array}{c}\text { Material } \\
\text { density, dry } \\
\left(\mathrm{kg} / \mathrm{m}^{3}\right)\end{array}$ & $\begin{array}{c}\text { Material } \\
\text { moisture } \\
\text { (on site), of } \\
\text { dry weight (\%) }\end{array}$ & $\begin{array}{c}\text { Bending } \\
\text { strength }\end{array}$ & $\begin{array}{c}\text { Bending } \\
\text { stiffness }\end{array}$ \\
MOE (MPa)
\end{tabular}

CBPB production. To reach the same strength as traditional CBPB boards on the market show, the cement content can be lower still.

Barley fibres need higher cement content than is the case for wood fibres, but this fulfilled, they can be used in $\mathrm{CBPB}$ production, pending $\mathrm{CO}_{2}$ injection.

The product is highly resistant to termites and microorganisms (mildew) and with good weathering properties.

The use of initial hardening by $\mathrm{CO}_{2}$ injection should be of interest in the production of CBPB;

The method gives higher initial strength with lower cement content than in traditional production and no need for energy use for curing of boards. The production is obviously environmentally friendly inasmuch that this/it binds $\mathrm{CO}_{2}$ and does not need external energy for heat treatment. In other words, it should be of great interest in the context of minimizing global warming effects.

Shorter production time as the boards, after formation pressure and $\mathrm{CO}_{2}$ injection of $3-4$ minutes, are strong enough to be stored without additional curing.

Formation pressure of $1.5 \mathrm{MPa}$ can be used for production with initial hardening by $\mathrm{CO}_{2}$, in traditional $\mathrm{CBPB}$ production formation pressure as high as 3 $\mathrm{MPa}$ is often needed.

Increased productivity as the traditional curing of CBPB will not be necessary. The potential for increased productivity in a $\mathrm{CO}_{2}$ based production as compared with a traditional production is estimated as high as 5 - 10 times.

Initial hardening by injection of $\mathrm{CO}_{2}$ from one side without using intermediate vacuum operations and with open edges of boards makes it possible to change existing production lines at a very limited cost.

Surface structuring of boards (embossment) can easily be done in a single sided $\mathrm{CO}_{2}$ injection production line.

\section{References}

[1] Anon, Panelguide (V3) Annex 2C Cement Bonded Particleboard (CBPB), Wood panel Industries Federation, Timber Trade Federation, TRADA, BRE. 
[2] Simatupang, M.H., Habighorst, C., Lange, H. and Neubauer, A. (1995) Investigation on the Influence of the Addition of Carbon Dioxide on the Production and Properties of Rapidly Set Wood-Cement Composites. Cement \& Concrete Composites, 17, 187-197. https://doi.org/10.1016/0958-9465(95)00009-2

[3] Dinwoodie, J.M. and Paxton, B.H. (1989) A Technical Assessment Cement Bonded Wood Particleboard. Construction and Building Materials, 3, 14-21. https://doi.org/10.1016/S0950-0618(89)80036-4

[4] Dinwoodie, J.M. (2000) Timber: Its Nature and Behaviour. 2nd Edition, E \& FN Spon, London. https://doi.org/10.4324/9780203477878

[5] Berger, R.L., Young, J.F. and Leung, K. (1972) Acceleration of Hydration of Calcium Silicates by Carbon Dioxide Treatment. Nature Physical Science, 240, 16-18. https://doi.org/10.1038/physci240016a0

[6] Young, J.F., Berger, R.L. and Breese, J. (1974) Accelerated Curing of Compacted Calcium Silicate Mortars on Exposure to $\mathrm{CO}_{2}$. Journal of the American Ceramic Society, 57, 394-397. https://doi.org/10.1111/j.1151-2916.1974.tb11420.x

[7] Sorochin, M.A., Shchurov, A.F. and Safonov, I.A. (1975) Study of the Possibility of Using Carbon Dioxide for Accelerating the Hardening of Products Made from Portland Cement. Journal of Applied Chemistry, 48, 1271-1274.

[8] Rostami, V., Shao, Y. and Boyd, A.J. (2012) Carbonation Curing versus Steam Curing for Precast Concrete Production. Journal of Materials in Civil Engineering, 24, 1221-1229. https://doi.org/10.1061/(ASCE)MT.1943-5533.0000462

[9] Soroushian, P., Won, J.-P., Chowdhury, H. and Nossoni, A. (2003) Development of Accelerated Processing Techniques for Cement-Bonded Wood Particleboard. Cement \& Concrete Composites, 25, 721-727. https://doi.org/10.1016/S0958-9465(02)00062-8

[10] Zhou, Y. and Kadem, D.P. (2002) Effect of Cement/Wood Ratio on the Properties of Cement-Bonded Particleboard Using CCA-Treated Wood Removed from Service. Forest Products Journal, 52, 77-81.

[11] Soroushian, P., Won, J.-P. and Hassan, M. (2013) Durability and Microstructure Analysis of $\mathrm{CO}_{2}$-Cured Cement-Bonded Wood Particleboard. Cement \& Concrete Composites, 41, 34-44. https://doi.org/10.1016/j.cemconcomp.2013.04.014

[12] Agopyan, V., Savastano, H., John, V.M. and Cincotto, M.A. (2005) Development on Vegetable Fibre-Cement Based Materials in Sao Paulo, Brazil: An Overview. Cement\& Concrete Composites, 27, 527-536. https://doi.org/10.1016/j.cemconcomp.2004.09.004

[13] Savastano Jr., H., John, V.M. and Caldas, A. (2001) Effect of Carbonation on Blast Furnace Slag Based Cement Reinforced with Cellulose Fibres. In: Figueiras, J., Juvendas, L. and Faria, R., Eds., Proceedings of the International Conference on Composites in Construction-CCC2001, Swets \& Zeitlinger, Lisse, 299-302.

[14] Bertos, M.F., Simons, S.J.R., Hills, C.D. and Carey, P.J. (2004) A Review of Accelerated Carbonation Technology in the Treatment of Cement-Based Materials and Sequestration of $\mathrm{CO}_{2}$. Journal of Hazardous Materials, 112, 193-205. https://doi.org/10.1016/j.jhazmat.2004.04.019

[15] E. Schmidt (1986) European patent N0. EP 0189127 B1. European Patent Office.

[16] BRI (2000) Cement Wood Composite Elements Produced with the GECA Concept -Final Technical Report, Tasks 3,4 and 5, Project Programme of Brite/Euram BES-2-2540 Contract No. BRST-CT-97-5131 DG12-CZJU, The Icelandic Building Research Institute Keldnaholt, Iceland. 
[17] EN 310:1993 Wood Based Panels-Determination of Modulus of Elasticity in Bending and Bending Strength. CEN Central Secretariat, Brussels.

[18] Fan, M.Z., Bonfield, P.W., Dinwoodie, J.M. and Breese, M.C. (1999) Dimensional Instability of Cement-Bonded Particleboard. Cement and Concrete Research, 29, 923-932. https://doi.org/10.1016/S0008-8846(99)00076-9 